\title{
The effect of shockwaves on mature and healing cortical bone
}

\author{
F. Forriol, L. Solchaga, J. L. Moreno, and J. Cañadell \\ Orthopaedic Research Laboratory, Department of Orthopaedic Surgery, Clinica \\ Universitaria, School of Medicine, University of Navarra, E-31080 Pamplona, Spain
}

\section{SUMMARY}

It has been proposed that high energy shockwaves could be used to creare microfractures in cortical bone. This quality might be exploited clinically to perforen closed osteotomies and promote healing in nonunion (15). However; no study has previously documented the effect of shockwaves on cortical bone "in vivo". We report an investigation designed to demonstrate the effect of shockwaves on mature cortical and healing bone. An osteotomy was performed on the tibiae of 37 lambs; two weeks later the operation site was exposed to shockwaves. Three weeks later the lambs were killed and specimens of the bone examined histologically and radiographically. Shockwaves had no effect on the periosteal surface of mature cortical bone, but on the endosteal surface some new trabecular bone was seen. Healing of bone was delayed by the shockwave therapy. We conclude that there is currently little place for shockwave treatment in clinical orthopaedics.

\section{RÉSUMÉ}

Le but de cette étude est d'évaluer les effets directs des ondes de choc de haute énergie sur l'os cortical du mouton, afin de préciser leur utilisation éventuelle en chirurgie orthopédique. Les animaux ont été divisés en plusieurs groupes selon le type d'intervention pratiqué, fenétres ou perforations, et selon le nombre et l'intensité des ondes de choc appliquées. Dans aucun des cas il n'y a eu de fragmentation ou d'érosion osseuse. Les ondes de choc ont entraîné une réaction intramédullaire au niveau de la corticale opposée aux orifices bombardés, sous forme de tissu mésenchymateux, siège de nombreuses cellules et d'une augmentation de la vascularisation. Les ondes de choc peuvent également perturber la reconstruction normale de l'os. Dans le groupe de contrôle les travées osseuses passent d'un bord l'autre de la fenêtre, contrairement à ce qui se produit chez les animaux bombardés où les travées proviennent de la corticale opposée. Nous avons noté que les ondes de choc, aussi bien à haute qu'à basse énergie, provoquent d'importants hématomes musculaires et sous-cutanés.

\section{INTRODUCTION}

Two uses have been proposed for high energy shockwaves in clinical orthopaedics. Firstly, to fragment polymethylmethacrylate cement and separate it from bone $[2,8,9$, 17-19], and secondly to cause microfractures of cortical bone. Such fractures could be 
used to perform closed "osteotomies" or to stimulate local haematoma formation and bone healing at the site of nonunion [15]. There are few side effects of this type of treatment $[2,7,12]$.

Both the suggested uses of shockwaves exploit their effect on cortical bone. However, little published data exists regarding the effect of high energy shockwaves on cortical bone in vivo. We have therefore undertaken a study to elucidate the effect of shockwaves on mature and healing cortical bone.

\section{MATERIALS AND METHODS}

\section{Study design}

We used one tibia from each of 37 lambs (Ovis aries), aged 2-3 months and weighing $16-22 \mathrm{Kg}$, to study the effects of shockwaves on cortical bone.

Each lamb was randomly chosen to receive either a Type a (drill holes) or Type b (window shaped) osteotomy of the proximal tibia (Fig. 1). Fifteen days after the creation of the osteotomy the operation site was bombarded with shockwaves at either low or high levels.

Three weeks following shockwave treatment and five weeks after osteotomy, the animals were killed. Specimens of the treated area of bone examined were evaluated by histological and radiographic methods to determine the effect of the treatment.

Details of each group regarding the type of osteotomy, shockwave treatment and number of animals are given in Table 1. Details of the creation of the osteotomy, shockwave treatment, histological and radiographic evaluation are given below.

\section{Osteotomy}

For the purposes of our study we refined a model of bone healing previously described by Shapiro [13]. Under general anaesthesia and using sterile technique one of two different operations was carried out on the tibia (Fig. 1).

Type a: With the aid of an image intensifier and using stab incisions, three holes were drilled in the lateral cortex of the tibia. A $4.5 \mathrm{~mm}$ drill bit was used. The holes were 1 $\mathrm{cm}$ apart and the most proximal hole was $3 \mathrm{~cm}$ from the joint line.

Type b: Through a medial approach a $1.5 \times 0.7 \mathrm{~cm}$ window of bone was removed from the lateral cortex of the tibia, $3 \mathrm{~cm}$ from the proximal joint line. The defect was thoroughly irrigated with normal saline to remove bony debris.

\section{Administration of shockwaves.}

A Siemens Osteostar was used. The shockwaves generated were transmitted from the aiming barrel to the subject via a water filled beachball. The shaved skin of the subject 
was covered with a conductive gel in each case. A Siremobile image intensifier was coupled to the barrel to allow precise location of the target osteotomy (Fig. 2).

Those animals receiving shockwaves (Table 1; groups I, III, IV) were treated fifteen days after the operation under general anaesthesia with the animal secured on an operating table. The site was located using the Siremobile image intensifier prior to initation of treatment.

For group a (three holes) the most proximal hole was bombarded with high energy, the distal hole with low energy and the central hole was not treated. For group b (window) the target point was the proximal border of the window.

Each animal undergoing shockwave treatment received 500 shocks at levels varying from $0.47 \mathrm{~mJ} / \mathrm{mm} 2$ (low energy) to $1.2 \mathrm{~mJ} / \mathrm{mm} 2$ (high energy). Only when shockwaves cross between tissues of different accoustic impedence is this energy released. The soft tissues about the tibiae studied were accoustically similar to the water in the "beach ball" and conductive gel. Thus this energy was coverted into tension waves and mechanical energy only at the site of the osteotomy $[1,2,4,5,6,11,14,16,19]$.

Shockwave treatment was given fifteen days after operation. It was thought that earlier treatment would disrupt haematoma formation and that later treatment might have no effect on newformed bone.

\section{Histological specimen preparation}

Animals were killed by intravenous injection of Thiopental $(1 \mathrm{~g})$ and potassium chloride (20 meq). The area of bone to be studied was excised and fixed in $10 \%$ formol for 10 days. An industrial saw was used to prepare specimens of suitable size which were dehydrated and infiltrated in a $1: 1$ mixture of alcohol/hydroxyethyl methacrylate for one week. After storage for 4 weeks the specimens were placed in hydroxyethyl methacralate and polymerised. Slices of $15 \mu \mathrm{m}$ were then obtained from the specimens and stained with Masson-Goldner and von Kossa's stains.

\section{Radiological studies}

The intramedullary, cortical and periosteal anatomy of all specimens was examined using Faxitron high-resolution microradiographic apparatus. All specimens were evaluated for changes resulting from shockwave therapy.

\section{RESULTS}

In none of the specimens studied was any effect seen on the periosteal surface of mature cortical bone. The findings regarding the effect on bone healing and the endosteal cortex are set out below. 


\section{Group I}

Control Drill-Holes. These holes received no shockwaves.

Histological section: Polarised light microscopy revealed woven bone bridging the drillhole (Fig. 3 a).

Radiographs: Trabecular bone was seen bridging the drill-hole (Fig. 3 b).

Bombarded Drill-Holes. These holes received either low or high energy shockwaves.

Histological section: Trabeculae were observed at the periphery of the drill-holes and on the endosteal surface of the opposite cortex. Mesenchymal tissue filled the central portion of the drill-hole and the medullary canal (Fig. 4 a).

Radiographs: Trabecular bone was identified at the point of impact of the shockwaves on the endosteal cortex (Fig. 4b, c).

\section{Group II}

Window shaped osteotomy. No shock-waves.

Histological section: Scanty woven bone was present with collagen fibres. Mesenchymal tissue occupied the centre of the window, covered by a periosteal bridge (Fig. 5).

\section{Group III}

Window shaped osteotomy. Low energy shock waves.

Histological section: Periosteal reaction was present at the periphery of the osteotomy. No periosteal bridging was seen Trabeculae were present adjacent to the opposite cortex, in the defect and beneath the periosteum (Fig. 6 a).

Radiographs: The medullary cavity was filled with trabeculae originating from impact point of shockwaves on the endosteal surface (Fig. 6b).

\section{Group IV}

Window shaped osteotomy. High energy shockwaves.

Histological section: Trabeculae were present at the periphery of the defect, with some in the medullary canal arising from the opposite cortex. The defect was bridged by periosteum. 


\section{DISCUSSION}

\section{Effect of shockwaves on mature cortical bone}

In common with previous research [7, 8, 9] we observed no significant erosion or fracture of the periosteal surface of cortical bone after treatment with shockwaves. Only with very high levels of energy has an effect on cortical bone been previously documented [14].

At the point of impact of shockwaves on the endosteum some growth of trabecular bone was demonstrated. It was difficult to see how this effect could be exploited clinically.

The different effects of shockwaves on the endosteal and periosteal surfaces may be explained by the accoustic impedence of the adjacent tissues.

The difference between the accoustic impedence of muscle and cortical bone is not large. Therefore little energy was imparted to the periosteal surface of the cortex. However, the difference between the accoustic impedence of fat in the medullary canal and the endosteal surface is greater. This may have led to greater energy transfer at this point, resulting in haematoma and trabecular bone formation.

\section{Effect of shockwaves on healing cortical bone}

Healing of bone was reduced in those specimens receiving shockwave therapy. We attribute this to disruption of the haematoma and the organization of collagen.

\section{CONCLUSION}

We have found that high energy shockwaves do not cause fracture of cortical bone "in vivo". Healing of bone is impaired by shockwaves. We consider it unlikely that shockwaves can be used to create closed osteotomies or to promote healing in nonunion as has been suggested [15].

\section{REFERENCES}

1. Atala A, Steinbock G (1989) Extracorporeal shockwave lithotripsy of renal calculi. Am J Surg 157: 350-358

2. Braun W, Claes L, Rüter A, Paschke C (1992) Effects of extracorporeal shockwaves on the stability of the interface between bone and polymethylmethacrylate: an in vitro study on human femoral segments. Clin Biomechanics 7: 47-54

3. Caillouette JT, Gorab RS, Klapper RC, Anzel SH (1991) Revision arthroplasty facilitated by ultrasonic tool cement removal. Orthop Review XX: 353-357

4. Chaussy C (1986) Extracorporeal shock wave lithotripsy, 2nd edn. Karger, Basel 
5. Delius M, Brendel W, Heine G (1988) A mechanism of gallstone destruction by extracorporeal shockwaves. Naturwissenschaften 75: 200-201

6. Dretler SP (1987) Laser fragmentation of ureteral calculi. In: SN Rous (ed) Stone diseases, diagnosis and management. Grune \& Stratton, Orlando

7. Graff J, Richter KD, Pastor J (1987) Wirkung von hoch-energetischen Stosswellen auf Knochengewebe. Verh Dtsch Ges Urol 39: 76

8. Karpman RR, Magee FP, Gruen TWS, Mobley T (1987) The lithotriptor and its potential use in the revision of total hip arthroplasty. Orthop Rev 16: 38-42

9. May TC, Krause WR, Preslar AJ, Smith MJ, Beauoin AJ, Cerdea AJ (1990) Use of high energy shockwaves for bone cement removal. J Arthroplasty 5: 19-22

10. Moore TJ (1970) A survey of the mechanical characteristics of skin and tissue in response to vibratory stimulation. IEEE Trans Man Machine Systems 11: 79-84

11. Reichenberger H (1988) Lithotripter systems. Proc IEEE 76: 1236-1241

12. Richter KD, Senge Th (1988) Die Wirkung extrakorporaler Stosswellen auf Beckengegend und Oberschenkel-Experimentelle Untersuchungen an Kaninchen und Beagle-Hunden. Zwischenbericht, Westfälische Wilhems Universität Münster. Dornier Med Technik

13. Shapiro F (1988) Cortical bone repair. J Bone Joint Surg [Am] 70: 1067-1081

14. Sukul DMKSK, Johannes EJ, Pierik EGJM, van Eijk GJWM, Kristelijn MJE (1992) The effect of high energy shockwaves focused on cortical bone: an in vitro study. J Surg Res 53 (in press)

15. Valchanou VD, Michailov P (1991) High energy shockwaves in the treatment of delayed and nonunions fractures. Int Orthop 15: 181-184

16. Vergunst H, Terpstra OT, Schröder FH, Matura E (1989) Assessment of shock wave pressure profiles in vitro: clinical implications. J Lithotripsy Stone Dis 1: 289-294

17. Weber U, Nietert M, Jacob E (1987) Possibilities and limits of ultrasound manipulation removal of bone cement. Aktuel Probl Chir Orthop 31: 347-353

18. Weinstein J, Wroble R, Loening S (1986) Revision total joint arthroplasty facilitated by extracorporeal shock wave lithotripsy: a case report. Iowa Orthop J 6: $121-124$

19. Weinstein JN, Oster DM, Park JB, Park SH, Loening S (1988) The effect of the extracorporeal shockwave lithotriptor on the bone cement interface in dogs. Clin Orthop 235: 261-267 


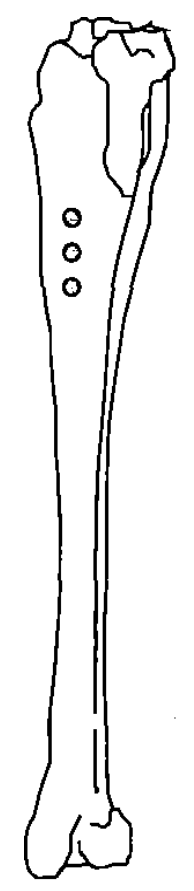

a)

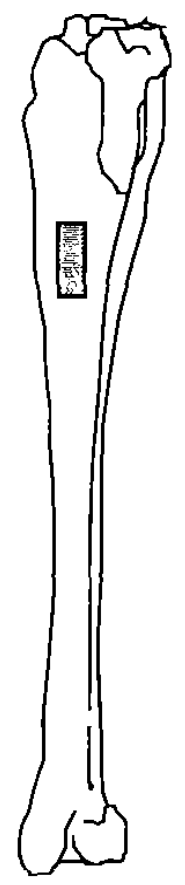

b)

Figure 1. Location of drill-hole (a) and window (b) osteotomies

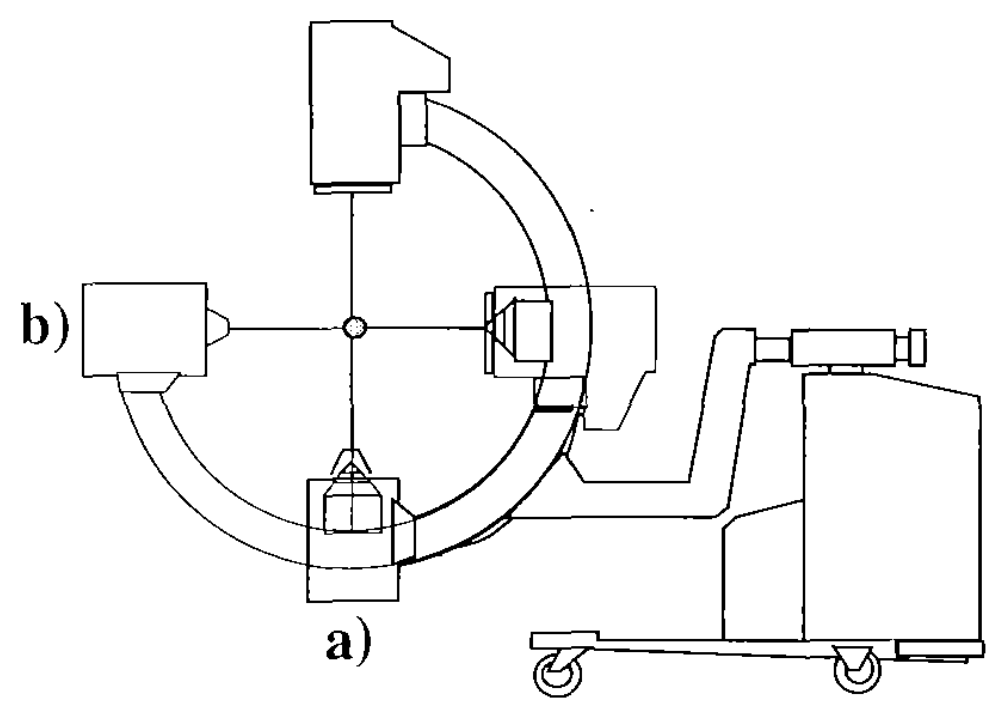

Figure 2. Targeting with image intensifier in anterior-posterior $(a)$ and medial-lateral (b) planes 


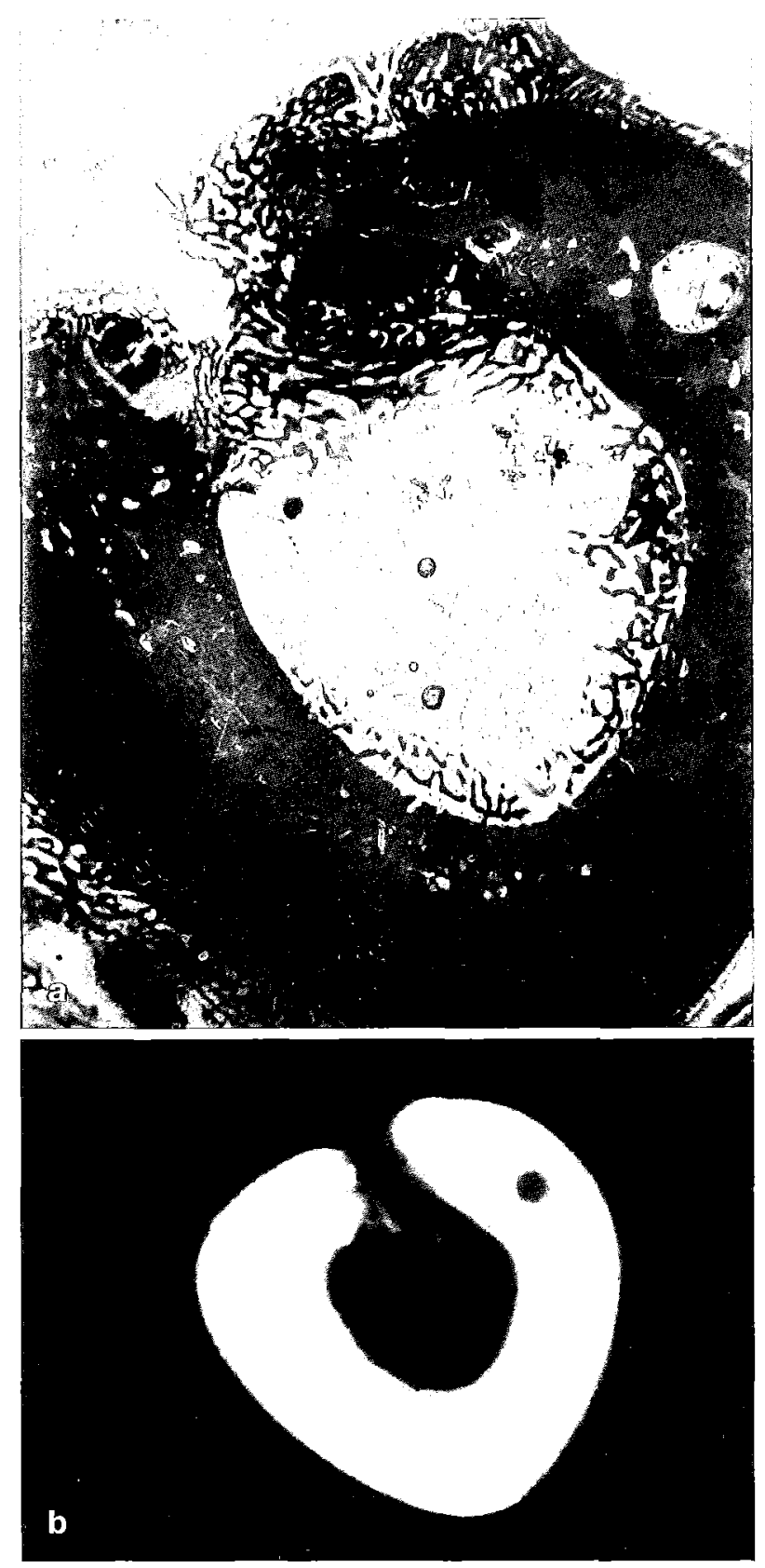

Figure 3. Histological section (a) and microradiograph (b) of control drill-holes 


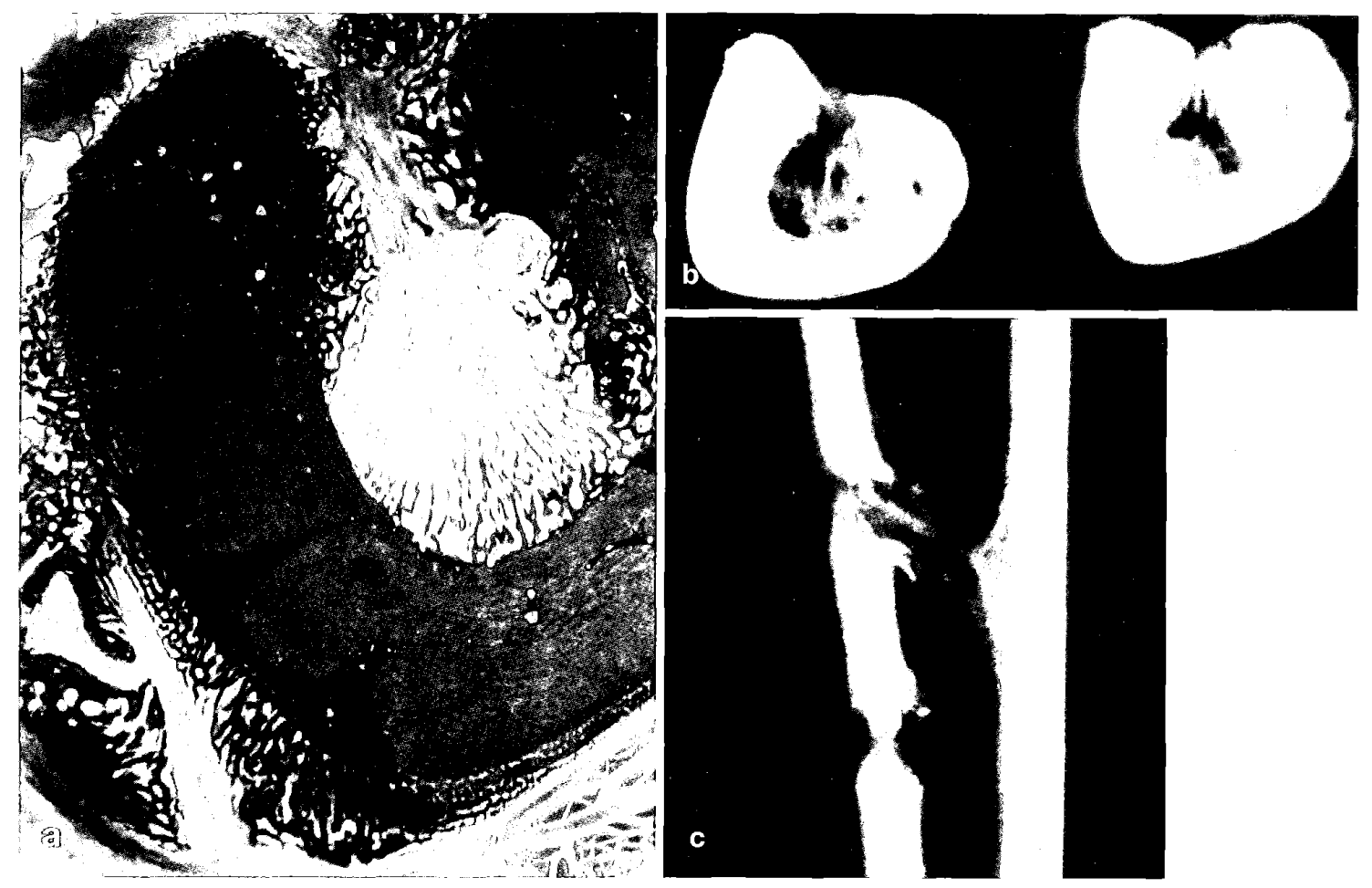

Figure 4. Histological section (a) and microradiographs (b, c) of bombarded drill-holes

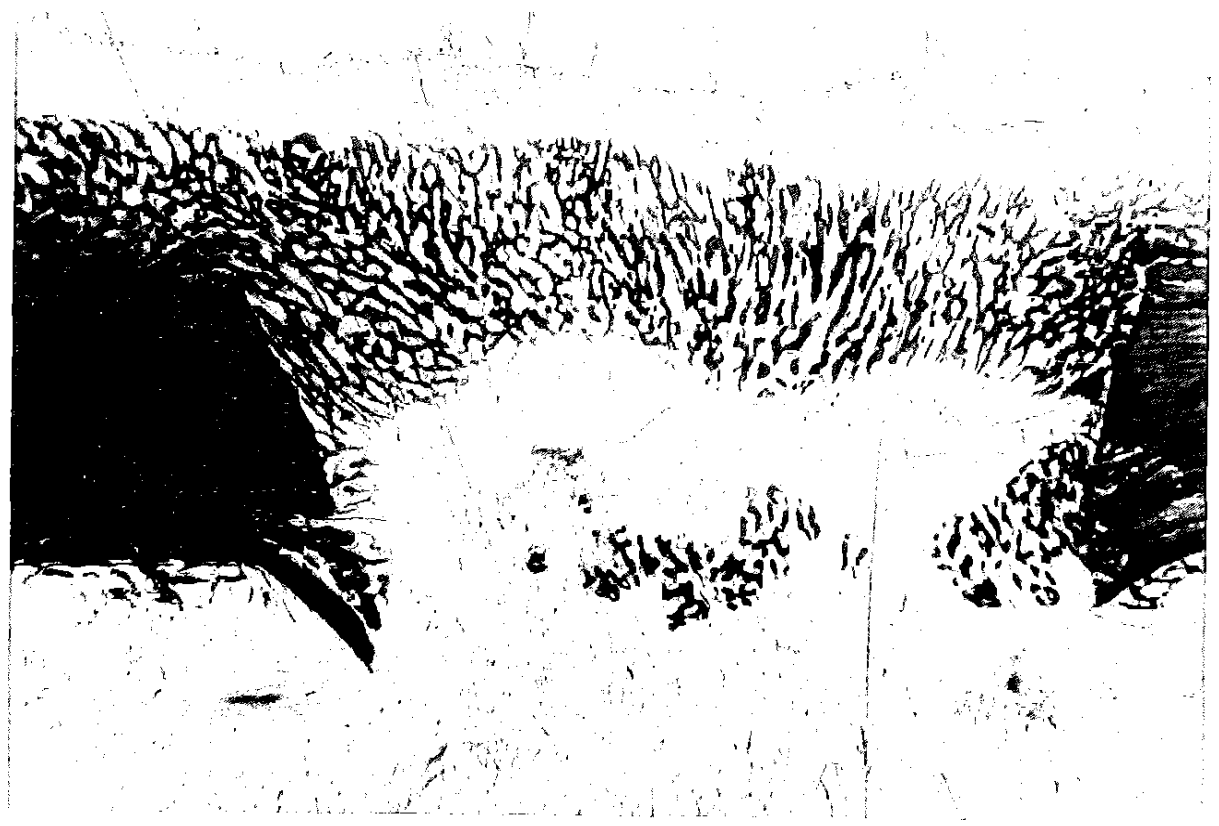

Figure 5. Histological section of control window shaped osteotomy 


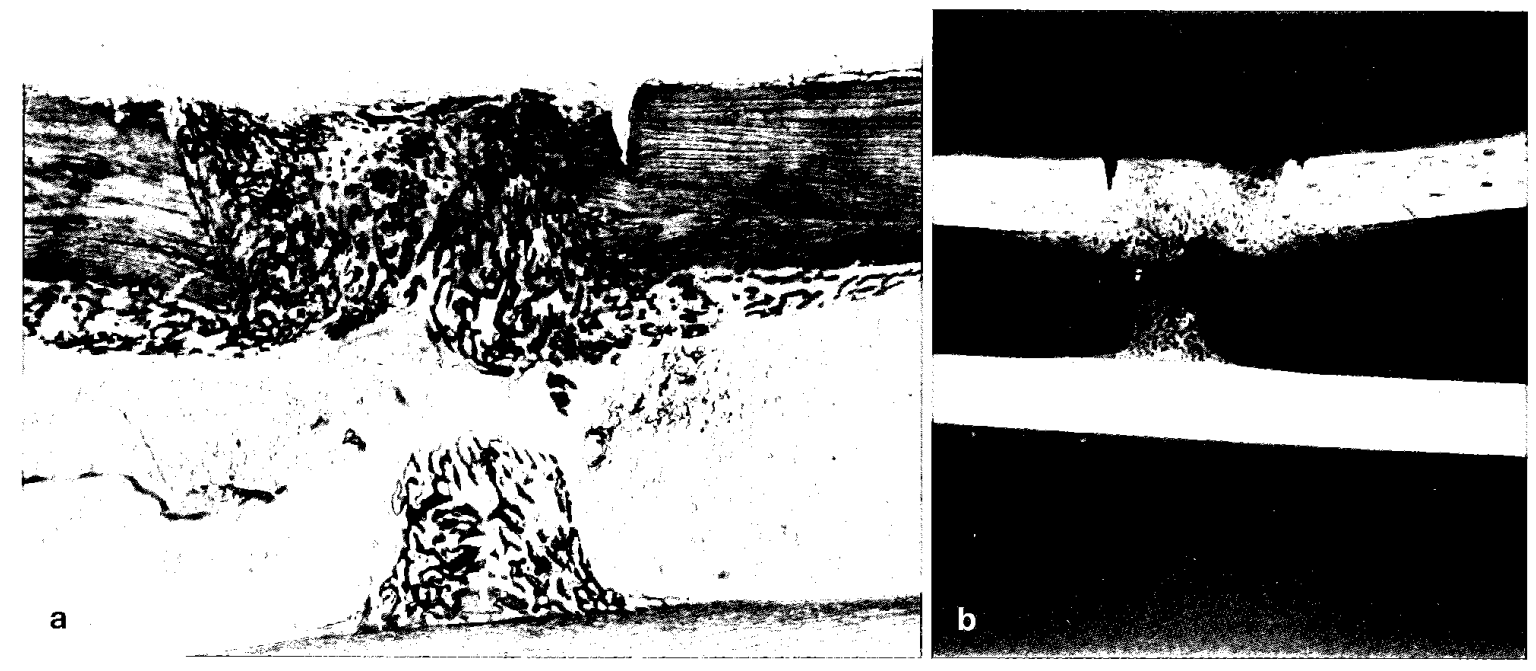

Figure 6. Histological section (a) and microradiograph (b) of bombarded window shaped osteotomy 


\begin{tabular}{|l|c|c|c|}
\hline \multicolumn{4}{|c|}{ Table 1. Composition of Groups I-IV } \\
\hline Group No & n & Osteotomy type & Shockwave level \\
\hline I & 10 & Drill-holes & High/low/none \\
\hline II & 11 & Window & None \\
\hline III & 8 & Window & Low \\
\hline IV & 8 & Window & High \\
\hline
\end{tabular}

